\title{
A practical approach to the assesment of manual handling equipment for cargo: multinational abrasives in Brazil
}

\author{
João Barbosa Neto ${ }^{\text {al }}$, Eduardo Aparecido Centeio ${ }^{a}$, Fernando de Sampaio Siqueira ${ }^{a}$, Rosimeire \\ Simprini Padula ${ }^{\mathrm{a}, \mathrm{b}}$ \\ ${ }^{a}$ Postgraduate Program in Ergonomics, Senac, São Paulo, SP, Brazil \\ ${ }^{\mathrm{b}}$ Universidade Cidade de São Paulo, R. Cesário Galeno, 448, São Paulo, Brazil
}

\begin{abstract}
The Manual Handling of Loads is an activity present in virtually all production system, when developed without ergonomic principles of design and sizing can generate several instances of discomfort and musculoskeletal disorders. This work was carried out to measure, set limits and risks and guide specifications for the cargo handling carts in a specific company, tracing the anthropometric profile of the productive population and performing a quantitative evaluation of forces and design models of cars used in the company.
\end{abstract}

Keywords: Manual handling, anthropometric, carts, dynamometry, cargo.

\section{Introduction}

The Manual Handling of Loads (MMC) contributes a large percentage of more than half a million occupational diseases reported annually in the United States [1].

The work involves relation musculoskeletal disorders stretches, contractions in the lumbar spine, shoulders and upper limbs. It can result from acute pain, disability requiring specialized medical treatment. American statistics show that lumbar spine and muscle problems are among the most reported cases [5].

Productive population of the company analyzed the period from 2000 to 2009 , 10\% were diagnosed musculoskeletal diseases, of which $78 \%$ are upper limb and $22 \%$ in the region of the spine. Scientific evidence shows that effective ergonomic interventions can reduce the physical demands of manual handling of loads (MMC), in work tasks, thereby reducing the incidence and severity of musculoskeletal system. The potential for reducing costs related to occupational diseases alone makes ergo- nomic interventions a powerful tool for the company in its productivity, quality and ultimately its competitiveness in business.

Often the production and productivity "lean" to see how best to use energy, equipment and most efficient way to perform the task.

\section{Approach}

Evaluate the manual handling of wheelbarrows at a leader in the abrasives segment industry of the São Paulo state.

\subsection{Method of the approach}

Were evaluated by measuring the height of all 179 employees of the production sector of wet grinding and dry grinding wheels with 173 males and 6 females.

The stature of the participants was measured by stadiometer, was used as a basis for assessing the anthropometric variables [2].

\footnotetext{
1 Address: Rua Pedro Ramos Julio, 57, ap105-03, Vila Santana, Mogi das Cruzes, SP, Brasil - CEP-08737240. Email:joaob_fisio@hotmail.com. Phone number (55) 1184229709
} 
For the evaluation of forces applied to the manual handling of the cars was accomplished as shown in Manual Material Handling Guidelines, Liberty Mutuals Group (2004)[3].

Measurements were taken on all models of stroller manual handling found in the company, such as handle bar height, diameter of the handle, dry weight, full weight, diameter of the castors, height of the deposits of material in the stands, distance traveled and frequency drive; dynamometry initial displacement and displacement in maintenance performed to pull and pushTables developed by [3] using the percentile capacity for females.

After the assessment was delivered to company specific guidelines for height, diameter and width of the handle and drives that exceeded recommended limits, presented in management meeting.

\section{Results}

The results show that $28.57 \%$ of the stands were full, with loads and forces exerted over the limits for the female population [4] and $64.28 \%$ below the threshold, among the cars with limits below the recommended $70 \%$ increase in load may have moved, because the force applied to the drive was equal to or less than half the recommended limit.

The variable diameter of the handle had $71.42 \%$ of the cars above recommendations, $14.28 \%$ in the recommended diameter and $14.28 \%$ in the other handle was nonexistent. The handlebar height was below the ideal height for the population at $78.57 \%$ of the cars above the optimum in $14.28 \%$ of cars and only $7.15 \%$ of the car it was as recommended. The width of the handle $71.42 \%$ were in agreement with the recommendation, they were 14.28 a width less than recommended and $14.28 \%$ in the handle was missing.

\section{Discussion}

With the results found that $100 \%$ of the cars were not quite ergonomically appropriate in at least one of the measures.

The dynamometer evaluation shows that if all the appropriate variables, we can increase the cargo handled, thus reducing the manual handling, saving time without exposing workers to risks.

This finding is important and shows the lack of ergonomics in equipment design and the enormous contribution in the preventive and productive that the inclusion of ergonomics in the design of the equipment brings to businesses.

\section{References}

[1] Ergonomic Guidelines for Manual Material Handling-Cal / OSHA DHHS (NIOSH) Publication No. 2007-131

[2] Geneva, Jürgens, HW, Aune, IA, and U. Peiper "International Data on Anthropometry," LATIN AMERICA - ARGENTINA, BRAZIL, CHILE International Labour Office, 1990.

[3] Manual Material Handling Guidelines, Liberty Mutuals Group (2004).

[4] Snook, SH and Ciriello, VM, "The design of manual handling tasks: revised tables of maximum acceptable weights and forces", Ergonomics, 34,9,1991

[5] http://www.osha.gov/pls/oshaweb/owadisp.show_document?p _id=346\&p_table=SPEECHES 